Some letters have been abbreviated for print. See www.cmaj.ca for full versions and competing interests.

\section{Re-rethinking the article by Thombs and colleagues}

We take issue with all four key reasons given by Thombs and colleagues ${ }^{1}$ to advise against routine screening for depression.

First, unacceptably high false-positive rates can result. To support this point, Thombs and colleagues offered one reference that claimed there are $50 \%$ falsepositive rates, whereas systematic reviews reveal the existence of quality tools with greater than $80 \%$ sensitivity and greater than $80 \%$ specificity where the false-positive rates are in a very acceptable $10 \%-20 \%$ range. $^{2}$

Second, screening absorbs valuable resources better spent elsewhere. This opinion is already undermined because numerous clinics use screening procedures where patients respond via touchscreen computers or kiosks. System set-up cost is modest but long-term use is cheap.

Third, there is no evidence that screening benefits patients. Carlson and colleagues $^{3}$ conducted a randomized controlled trial in which screened patients had better emotional outcomes than non-screened patients. Interestingly, one of the authors advising against screening in the CMAJ article also attempted to negate the positive outcomes of the Carlson and colleagues ${ }^{3}$ study in a letter to the editor. ${ }^{4}$ Furthermore, Thombs and colleagues consider only improved patient outcomes as a justification for screening, and they ignore the social justice of equal access to care and that routine screening allows for databased resource allocation.

Fourth, treatment for depression is not very effective. The authors cite only evidence that selective serotonin reuptake inhibitors are of limited use, but they ignore the impressive literature on the effects of psychological therapies on depression. ${ }^{5}$ Also detrimental to the stance of the authors are two systematic reviews revealing that psychological treatment is most effective for high levels of depression, and that psychological treatment for depression and anxiety in patients with cancer was three times as effective when patients had first been screened for actual existence of depression and anxiety. ${ }^{6}$

Last, why focus only on screening for depression when there other treatable types of distress, like anxiety or symptom burden, that affect patients' quality of life?

\section{Wolfgang Linden PhD}

\section{Andrea Vodermaier PhD}

Professors, University of British Columbia, Vancouver, BC

\section{References}

1. Thombs BD, Coyne JC, Cuijpers P, et al. Rethinking recommendations for screening for depression in primary care. CMAJ 2012;184:413-8.

2. Vodermaier A, Linden W, Siu C. Screening for emotional distress in cancer patients: A systematic review of assessment instruments. J Natl Cancer Inst 2009;101:1464-88.

3. Carlson LE, Groff SL, Maciejewski O, et al. Screening for distress in lung and breast cancer outpatients: a randomized controlled trial. J Clin Oncol 2010;28:4884-91.

4. Palmer SC, van Scheppingen C, Coyne JC. Clinical trial did not demonstrate benefits for screening patients with cancer for distress. $J$ Clin Oncol 2011;29:e277-8

5. Driessen E, Cuijpers P, Hollon SD, et al. Does pretreatment severity moderate the efficacy of psychological treatment of adult outpatient depression? A meta-analysis. J Consult Clin Psychol 2010;78: 668-80.

6. Linden W, Girgis A. Psychological treatment outcomes for cancer patients: What do meta-analyses tell us about distress reduction? Psychooncology 2011; Sept. 1 [Epub ahead of print].

CMAJ 2012. DOI:10.1503/cmaj.112-2023

\section{The authors respond}

Linden and Vodermaier ${ }^{1}$ claim that the rate of false-positives with screening for depression is "very acceptable." Whether a false-positive rate is acceptable depends on the prevalence of disease in the population being screened. Given the prevalence of depression in a typical primary care setting and that about half of patients with depression are typically identified without screening, ${ }^{2}$ most individuals who screen positive in primary care will not have depression (Figure 1). This is hardly acceptable when one considers the potential harms to patients with falsepositive screens and resultant costs to society. ${ }^{2,3}$ The cost of screening includes assessments, consultations, treatment and follow-up services and is much greater than the cost of administering a questionnaire. ${ }^{4,5}$ Linden and Vodermaier cite a single randomized controlled trial (RCT) in patients with cancer, ${ }^{6}$ which did not improve depression scores at follow-up, to support routine screening of depression in primary care. That trial was described as a screening trial, but it did not use depression or distress screening scores to determine which patients would be offered a psychosocial evaluation. Rather, patients received a consultation if they requested one, regardless of their questionnaire results. Referrals for supportive services were potentially recommended to patients following consultation based on many different factors, including, but not limited to, symptoms of depression or anxiety, distress, pain, fatigue, drug or alcohol use, as well as concerns about transportation, parking, and groceries.

Linden and Vodermaier suggest that screening could provide the "social justice of equal access to care." Access to care would achieve social justice if the benefits of that care outweighed its harms, but this has not been shown for screening for depression. Linden and Vodermaier appear to agree that treatment for depression is most effective when patients have more severe symptoms of depression. Yet most patients who screen positive, but are not otherwise recognized as having depression, will have relatively low depression severity $^{2}$ (as described in our article). ${ }^{2}$

No RCT results have shown that patients who are screened for depression have better depression outcomes than patients who are not screened for depression, and there have been many 


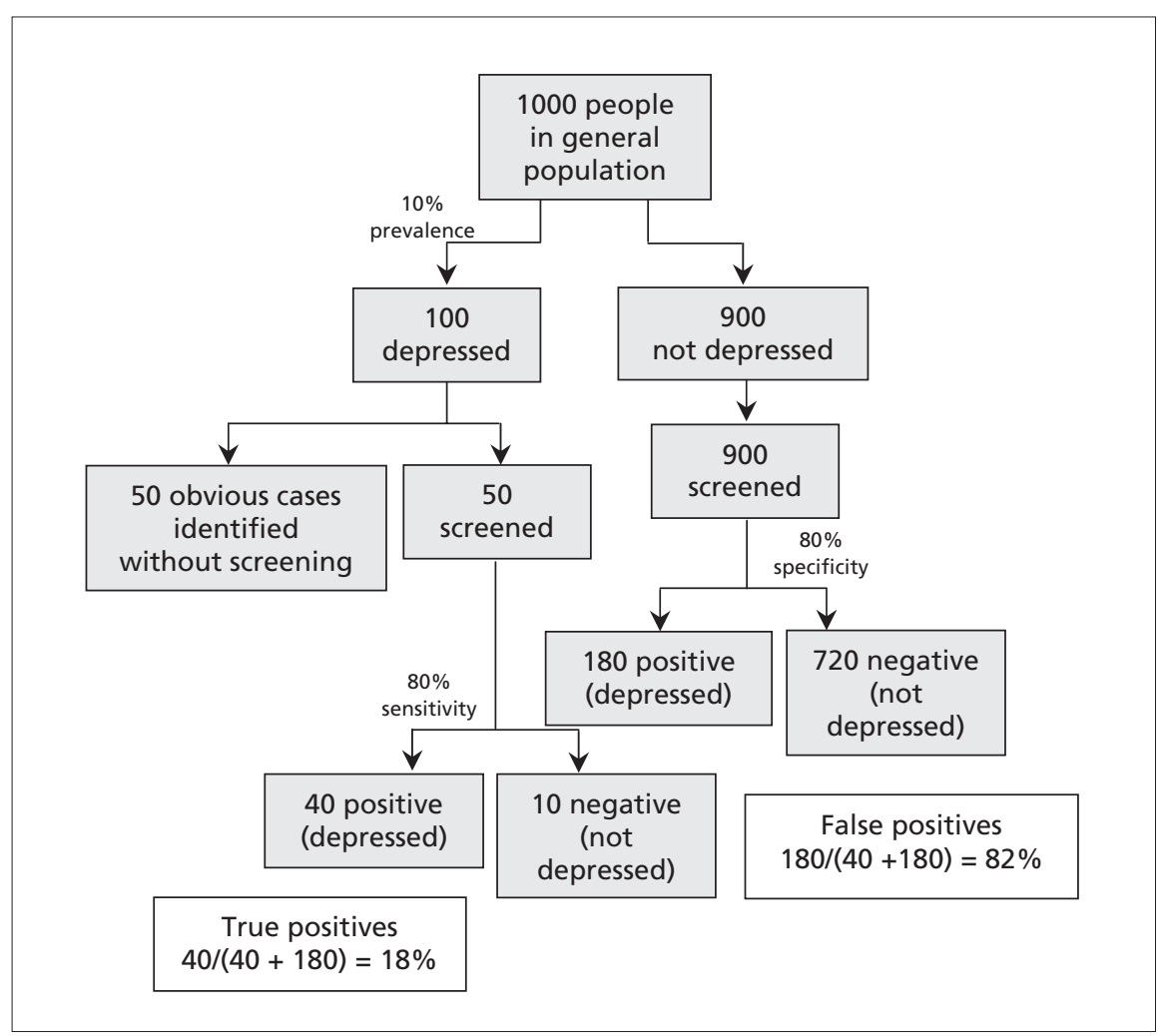

Figure 1: Percentage of true- and false-positive screens among patients who screen positive for depression.

negative trials. ${ }^{2}$ Thus, we re-assert that the available evidence does not support screening for depression as routine health policy.

\section{Brett D. Thombs PhD}

Associate Professor, Department of Psychiatry, Mcgill University and Senior Investigator, Lady Davis Institute of Medical Research, Jewish General Hospial, Montréal, Que.

James C. Coyne PhD, Pim Cuijpers

$\mathbf{P h D}$, Peter de Jonge PhD, Simon

Gilbody DPhil, John P.A. Ioannidis MD

DSc, Blair T. Johnson PhD, Scott B.

Patten MD PhD, Erick H. Turner MD,

Roy C. Ziegelstein MD

\section{References}

1. Linden W, Vodermaier A. Re-rethinking the article by Thombs and colleagues [letter]. CMAJ 2012; 184:438.

2. Thombs BD, Arthurs E, El-Baalbaki G, et al. Risk of bias from inclusion of patients who already have a diagnosis or are undergoing treatment for depression in diagnostic accuracy studies of screening tools for depression: systematic review. BMJ 2011; 343: 44825 .

3. Thombs BD, Coyne JC, Cuijpers P, et al. Rethinking recommendations for screening for depression in primary care. CMAJ 2012;184:413-8.

4. UK National Screening Committee. Second report of the UK National Screening Committee. London (UK): Department of Health; 2000.
5. Raffle A, Gray M. Screening: evidence and practice. New York (NY): Oxford University Press; 2007.

6. Carlson LE, Groff SL, Maciejewski O, et al. Screening for distress in lung and breast cancer outpatients: a randomized controlled trial. J Clin Oncol 2010;28:4884-91.

CMAJ 2012. DOI:10.1503/cmaj.112-2024

\section{Hospital parking fees}

In 1999, while working at a local hospital, I conducted a small parking survey, which included 81 patients, out of concern that parking fees were having an impact on health care. I found $82.7 \%$ of patients were prevented from parking at hospital sites because of the cost of parking. Even more shocking were the methods of coping employed by patients due to their inability to pay parking fees. Many (86.4\%) parked off hospital sites and walked; $42 \%$ chose not to attend for an appointment or program; $30.9 \%$ attended on a few occasions then stopped; and $35.8 \%$ attended only when they had money to pay for parking.

I brought the results to the attention of the hospital administration and to the
Ministry of Health. That parking fees were seen as a source of future revenue became clear to me after meeting with various members of the administration of the Humber River Regional Hospital. The Ministry of Health pointed out that public hospitals are autonomous corporations that are run by boards of governors and that the parking issue is outside the jurisdiction of the Ministry of Health. This position flies in the face of the Public Hospitals Act, ${ }^{1}$ which states,

In making a decision in the public interest under this Act, the Lieutenant Governor in Council or the Minister, as the case may be, may consider any matter they regard as relevant including, without limiting the generality of the foregoing, ... (b) the proper management of the health care system in general; ... (d) the accessibility to health services in the community where the hospital is located.

This statute clearly indicates that the Ontario government has the power to step in and stop a practice that limits "accessibility to health services in the community where the hospital is located." The CMAJ editorial "Parkingcentred health care" ${ }^{2}$ indicates that nothing has changed since 1999 .

Surely the provinces and hospitals can do better than this. People are not attending for treatment because they can't afford to pay for parking.

John F. Thornton MD

Psychiatrist, private practice, Toronto, Ont.

\section{References}

1. Public Hospitals Act, RSO, 1990, c C-40, s 9.1 (1)

2. Kale R. Parking-centred health care [editorial]. CMAJ 2011;184:11.

\section{CMAJ 2012. DOI:10.1503/cmaj.112-2025}

In Ontario, the provincial government funds $74 \%$ of the cost of operating hospitals. Hospitals generate the remaining $26 \%$ of operating funds themselves, and parking fees are one of the most common ways of making up the difference. If $1 \%$ of hospital revenue comes from parking, as the interim editor of $C M A J$ suggests, ${ }^{1}$ then eliminating that revenue would create a funding hole as deep as \$230 million in Ontario alone. With Ontario's provincial government running a deficit of more than $\$ 16$ billion this year, while also signalling a 